East African Medical Journal Vol. 81 No. 8 August 2004

IMMUNOHISTOCHEMICAL ANALYSIS OF HODGKIN'S DISEASE IN KAMPALA, UGANDA

L. K. Tumwine, MBChB, MMed, Registrar, Department of Pathology, Makerere Medical School, P.O. Box 7072, Kampala, Uganda

\title{
IMMUNOHISTOCHEMICAL ANALYSIS OF HODGKIN'S DISEASE IN KAMPALA, UGANDA
}

\section{K. TUMWINE}

\begin{abstract}
Background: Histopathological examination remains crucial for diagnosis and classification of Hodgkin's disease (HD) but poses problems when characteristic features of HD are not present and hence the value of immunohistochemistry. Experience with immunohistochemistry in developing countries is limited due to cost.

Objective: To describe the immunophenotypic and histologic types of Hodgkin's disease in Kampala, Uganda

Design: A cross-sectional study.

Setting: Makerere University Medical School, Department of Pathology.

Methodology: Two hundred formalin fixed, paraffin- embedded biopsies, which had been previously diagnosed as Hodgkin's disease in the Makerere University, Department of Pathology from 1980-2000, were re-assessed with haematoxylin and eosin. The sections were then subjected to immunohistochemistry using monoclonal antibodies: leucocyte common antigen (CD45), antibodies to Reed-Sternberg cells (CD15, CD30) and to B cells (CD20).

Results: Of the 200 biopsies, $171(71.3 \%)$ were diagnosed as Hodgkin's disease using immunohistochemistry. The mean age of the 171 cases was 26.1 (SD 16.2) years; mode 20.0; median 22.5 years. The $15-24$ year age group was most affected $(47.2 \%)$. There were more males $(65.9 \%)$ than females and most were Baganda who are the main tribe in the central region of Uganda. Mixed cellularity $(35.7 \%)$ and lymphocyte depleted $(24.6 \%)$ HD were the commonest histological types. Classic HD (CD30, CD 15, CD20, CD45) was the most commonest $(\mathbf{7 7 . 8 \%})$ immunophenotype.

Conclusion: Classic Hodgkin's disease (CD30, CD 15, CD20 and CD45) is the most commonest immunophenotype in Kampala, Uganda, and mixed cellularity and Iymphocyte depleted are the main histologic subtypes.
\end{abstract}

\section{INTRODUCTION}

Hodgkin's disease is the third most common Iymphoma (after Burkitt's lymphoma, and other nonHodgkin's lymphomas) in Kampala, Uganda, according to the Cancer Registry kept at the Makerere Medical School(1). The incidence of the disease seems to have remained static in contrast to other lymphomas in which there has been a dramatic rise in incidence since the beginning of the HIV/AIDS pandemic(2).

The prognosis of Hodgkin's disease largely depends on accurate histopathological diagnosis and classification(3). Therapeutic approaches of Hodgkin's disease are also largely dependent on clinical stage. However histopathological diagnosis poses some problems for the histopathologist when the classical histological features of Hodgkin's disease are not seen(3). Histologically, the diagnosis of Hodgkin's disease is based on the identification of malignant Reed-Sternberg cells in a background of lymphocytes, eosinophils, neutrophils, plasma cells and macrophages (4).

There are four histological subtypes (lymphocyte predominant, nodular sclerosing, mixed cellularity and lymphocyte depleted) according to the Rye classification(5). This classification is important for prognosis. Lymphocyte predominant has the best prognosis followed by nodular sclerosing, mixed cellularity and lymphocyte depleted respectively. In 1994, a new iymphomaclassification, the Revised European-American Lymphoma Classification (REAL) was agreed based on morphologic, immunologic, and genetic criteria(6). It places Hodgkin's iymphoma into two groups: classical Hodgkin's disease and nodular lymphocyte predominant Hodgkin's disease(6). Classical Hodgkin's disease consists of nodular sclerosing, mixed cellularity, and lymphocyte depletion.

In the developed countries immunohistochemistry is being used for diagnosis in problematic, borderline and in unusual cases to resolve the diagnosis. Immunohistochemical techniques are used to detect antigenic molecules in situ in human cell and tissue samples, and have been used widely in recent years both in diagnostic pathology and in research into human disease. Monoclonal antibodies (antibodies of single specificity, generated from immortalisation of plasma B cells in vitro) are essential tools for detecting antigenic molecules. Immunohistochemical studies have mapped the expression of various $\mathrm{CD}$ antigens to specific cells and tissues. This has led to their use as cell or tissue markers in the histopathology diagnosis of lymphomas. 
Immunophenotype refers to the antigenic profile for example B cells express CD20 and CD79a(4). Many studies have been done in western countries on immunophenotype of Reed-Sternberg (RS) cells in an attempt to define the origin of these cells (5-7). In fact some recent studies have defined the origin of $\mathrm{RS}$ cells as B-lymphocytes $(8,9)$. For the diagnosis of Hodgkin's disease, combinations of a number of markers are used. These include activation antigens (CD30, CD15, CD25, and CD71), HLA related markers (CD74, HLA-DR), T and $B$ cell associated antigens UCHL-1/CD7 and CD20/ L26, and leucocyte common antigen (CD45).

More recently Carbone and others (10) have shown that RS cells and their morphologic variants express CD40 in all the 171 cases of Hodgkin's disease studied irrespective of the histological types.

Immunohistochemically, Hodgkin's disease falls into two broad categories. The first one is the classical Hodgkin's disease with the classical RS cells, which have an antigen profile of $\mathrm{CD}^{\circ} 0^{+}, \mathrm{CD} 15^{+}, \mathrm{CD} 20^{-}$, and $\mathrm{CD}_{45}$. The second is nodular lymphocyte predominant(11) Hodgkin's disease with the putative neoplastic cells lymphocytic $(\mathrm{L})$ and histiocytic $(\mathrm{H})$ cells, which are $\mathrm{B}$ cells with an antigenic profile of $\mathrm{CD}^{-}, \mathrm{CD} 15^{\circ}, \mathrm{CD} 20^{+}$, and $\mathrm{CD} 5^{+}$. Monoclonal antibodies have also been used to distinguish Hodgkin's disease from other lymphomas that histologically show a striking similarity to Hodgkin's disease such as T-cell/histiocyte-rich B-cell lymphoma and anaplastic large cell lymphoma.

This work was part of a larger study that evaluated the reliability of haematoxylin and eosin using immunohistochemistry as gold standard(4). The objective of this paper, is to describe the immunophenotypic and histologic types of Hodgkin's disease in an African population in Kampala, Uganda.

\section{MATERIALS AND METHODS}

Study design and setting: This cross sectional study was carried out in the Makerere University Medical School, Department of Pathology. The department renders the bulk of biopsy services for the whole country and autopsy services for Mulago Hospital handling over 6000 biopsies per year. All the biopsies received from hospitals and health units including Mulago Hospital are kept as formalin-fixed, paraffin embedded tissue blocks.

Study population: This consisted of biopsy specimens received and preserved as formalin-fixed, paraffin embedded tissues, in the Makerere University Department of Pathology, from 1980 2000 inclusive.

Sampling procedure: The first 200-biopsy specimens where a diagnosis of Hodgkin's disease had been made by a histopathologist using haematoxylin and eosin from 1980 to 2000 inclusive were consecutively entered into the study. Any poorly fixed sections, those with extensive tissue or cell necrosis were excluded. The specimens for the study were retrieved from the general pool of formalin- fixed, paraffin-embedded tissue blocks in the Department of Pathology. They were screened and assessed; and those meeting the inclusion criteria were entered into the study.
Data collection methods: Each specimen was given a serial number and tissue blocks were then subjected to routine $H$ \&E and reinterpreted by the investigator using the criteria proposed by Luke's and Butler and the Rye conference (12-14). Where it was not clear as to whether the diagnosis was nodular sclerosing Hodgkin's disease, Gordon and Sweets' reticulin method (15) for reticulin fibres was employed. The histologic diagnosis of each specimen was entered on to a data entry form. The same tissue blocks were subjected to monoclonal antibodies (16) CD15, CD20, CD30, and CD45 and an immunohistochemical diagnosis made. The results for each specimen were entered on to the data entry form.

Data management and analysis: Data were collected and entered into the computer using EPI INFO software for storage and initial analysis. Further analysis was done using SPSS software. The data were summarised in frequency tables, means, graphs and charts.

Immunohistochemical diagnosis: The diagnosis of Hodgkin's disease was confirmed by staining the sections with monoclonal antibodies, which bind to antigens expressed on the Reed Sternberg cells. Panels of four antibodies were used including antibodies to $\mathrm{CD} 15, \mathrm{CD} 30, \mathrm{CD} 45$, and to $\mathrm{B}$ cell antigen $\mathrm{CD} 20$

\section{RESULTS}

Socio demographic characteristics of study population: The age distribution of the 171 patients, diagnosed as having Hodgkin's disease by immunohistochemistry is shown in figure 1. The majority of patients with Hodgkin's disease were in the 15-24 year age group.

Figure 1

Age (years) distribution of patients with Hodgkin's disease



Age was not recorded in three biopsies

Sex distribution: There were $112(65.9 \%)$ males and 58(34.1\%) females with Hodgkin's disease during the period of review, showing a male to female ratio of 1,93:1. One patient had no sex recorded. The Baganda were the most frequent tribe affected by Hodgkin's disease accounting for $61(35.7 \%)$ of the cases followed by the Acholi 12(7\%), Etesot 12(7.0\%) and others 36(21.1\%). 


\section{Figure 2}

\section{Histological subtypes of Hodgkin's disease confirmed in 171 specimens by immunohistochemistry}

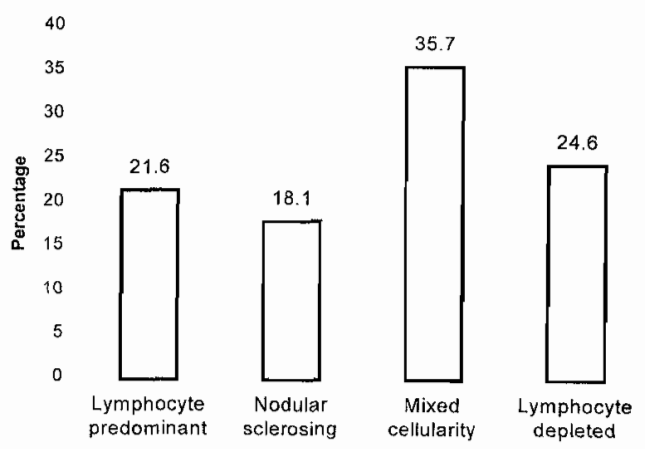

Most of the cases of Hodgkin's disease were of mixed cellularity $(35.7 \%)$, followed by lymphocyte depleted $(24.6 \%)$, lymphocyte predominant $(21.6 \%)$ and nodular sclerosing (18.1\%).

Immunological subtype: After immunostaining, 171 (71.3\%) of the 200 specimens were positive for Hodgkin's disease. These have been classified into their immunological subtypes as shown in Table 1.

Table 1

Immunological subtypes of Hodgkin's disease

\begin{tabular}{lc}
\hline Subtype & No. $(\%)$ \\
\hline $\begin{array}{l}\text { Classic Hodgkin's disease } \\
\text { (CD30+, CD 15+, CD20, CD45) }\end{array}$ & $133(77.8)$ \\
$\begin{array}{l}\text { Nodular lymphocyte predominant } \\
\text { Hodgkin's disease }\end{array}$ & $38(22.2)$ \\
$\left(\mathrm{CD} 30^{\circ}, \mathrm{CD} 15^{-}, \mathrm{CD} 20^{+}, \mathrm{CD} 45^{+}\right)$ & \\
\hline
\end{tabular}

Total

Classic Hodgkin's disease is defined as the immunophenotype of CD $30^{+}, \mathrm{CD}^{\circ} 5^{+}, \mathrm{CD} 20{ }^{\circ}, \mathrm{CD} 45^{-}$, which also happens to be the immunophenotype of Reed Sternberg cells. Classic Hodgkin's disease consists of: mixed cellularity, lymphocyte depleted and nodular sclerosing histological subtypes.

\section{DISCUSSION}

The aim of this study was to classify the different immunophenotypic and histologic types of Hodgkin's disease in Kampala, Uganda. In the current study, Hodgkin's disease appears to affect mainly young people in the 15-24 year age group accounting for $47.2 \%$ of the cases. This finding conforms to the pattern observed by others in Uganda(17), Kenya(18) and Zimbabwe(19). There was a male preponderance with a male to female ratio of 1.93 to 1 , a finding similar to what other workers have reported from Kenya(18), Uganda(1) and South Africa(20). The Baganda were the most common tribe affected by Hodgkin's disease with $61(35.7 \%)$ of the cases, followed by the Acholi (7\%), Etesot (7\%), Langi (6.4\%), Soga (6.4\%), Lugbara (6.4\%), Nkore (5.9\%) and others. The high percentage of the Baganda might be a reflection of the tribal distribution of the Mulago Hospital patient population since Mulago is located within Uganda's central region where the Baganda are the majority tribe. Immunophenotypes: The results show that classic Hodgkin's disease (with immunophenotypes CD30', $\mathrm{CD}^{+} 5^{+}, \mathrm{CD} 20^{-}$and $\mathrm{CD} 45^{-}$) is the common immunological subtype of Hodgkin's disease in Kampala, Uganda accounting for $77.8 \%$ of the cases. Classic Hodgkin's disease encompasses the nodular sclerosing, mixed cellularity and lymphocyte-depleted types. The pattern conforms to the study by von-Wasielewski et al. in 1997, in which $83 \%$ of 1751 cases of Hodgkin's disease showed the classic immunophenotype(21). Similar results have been obtained by re-analysing results from Costa Rica(22) and Malaysia(23). In the Costa Rican study classic Hodgkin's disease accounted for $87.5 \%$ of the cases while in Malaysia a similar result (84\%) was observed. Unfortunately there were no African studies of immunophenotyping of Hodgkin's disease with which to compare the findings of the current study.

Histological subtypes: The majority $61(35.7 \%)$ of the 171 cases of Hodgkin's disease belonged to the mixed cellularity group followed by lymphocyte depleted with $42(24.6 \%)$. This finding is comparable to the types reported by Dhru et al. (17), Olweny et al(24) and Wright(25) in Uganda in the 1960s and 1970s. Similar observations have been made elsewhere in Kenya(18), and amongst black Zimbabweans(19) and South Africans(20). This is in contrast to findings in developed countries where nodular sclerosing and lymphocyte predominant are the main histological types(26).

The reason for the preponderance of these poor prognostic histological subtypes of Hodgkin's disease in the developing countries is not well understood but has been linked to possible exposure to a hypothetical infection at a very young age (25). This is in contrast to the developed countries where children are protected from infection and therefore Hodgkin's disease does not occur until later in life when there is a better host response and histological subtypes, with a better prognosis, predominate. The infectious agents affecting people in the developing world include Epstein Barr virus and endemic malaria(27). It has also been postulated that repeated exposure to malaria parasites from birth leads to defects in immunity(25). Recently Taylor(28) has summarised the available evidence linking Epstein Barr Virus (EBV) and Hodgkin's disease although not as strong as that between EBV and Burkitt's lymphoma and nasopharyngeal carcinoma.

All in all, the real reasons for the differences in the histological types of Hodgkin's disease in the develuped and developing countries are not yet established and the mystery continues. 
In conclusion, Classic Hodgkin's disease $\left(\mathrm{CD} 30^{+}\right.$, $\mathrm{CD} 15^{+}, \mathrm{CD}_{20} 0^{+}$and $\mathrm{CD}_{4} 5^{+}$) is the most common immunophenotype in Kampala, Uganda, and mixed cellularity and lymphocyte depleted are the main histologic subtypes.

\section{ACKNOWLEDGEMENT}

To Austrian Scholarship Programme Horizon T300 for financial support.

\section{REFERENCES}

1. Wabinga, H.R., Parkin, D.M., Wabwire-Mangen, F. and Nambooze, S. Trends in cancer incidence in Kyadondo county, Uganda. 1960-1997. Brit. J. Cancer 2000; 82:1585-1592.

2. Parkin, D.M., Wabinga, H., Nambooze, S., Wabwire-Mangen, F. AIDS related cancers in Africa: maturation of the epidemic in Uganda. AIDS. 1999; 13:2563-2570.

3. Chan, J. K.C., Banks, P., Clearly, M.L. et al. A revised European-American classification of lymphoid neoplasm proposed by the International Lymphoma study group. Amer. J. Clin. Pathol. 1994; 103:543-560.

4. Kuzu, I.. Delsol, G., Jones, M., Gatter, K.C. and Mason, D.Y. Expression of Ig-associated heterodimer (mb-l and B29) in Hodgkin's disease. Histopathology. 1993; 22:141-144.

5. Mir, R. and Kahn, L.B. Immunohistochemistry of Hodgkin's disease: A study of 20 cases. Cancer. 1983; 52:2064-2071.

6. Strauchen, A.J. and Dimitriu-Bona, A. Immunopathology of Hodgkin's disease, characteristics of Reed Sternberg cell with monoclonal antibodies. Amer. J. Pathol. 1986; 123:293-300.

7. Popema, S., DeJong, B., Atmosoerodjo, J., Idenburg, V., Visser, L., and Delay, L. Morphologic, immunologic, enzyme histochemical and chromosomal analysis of a cell line derived from Hodgkin's disease: Evidence of B cell origin of Reed Sternberg cells. Cancer. 1985; 55:683-690.

8. Carbone, A. and Ghoghini, A. Can Reed Sternberg cells of classic Hodgkin's disease be considered B cells? Adv. Clin. Path. 1999; 3:3-9.

9. Agnarsson, A.B. and Kadin, M.E. The immunophenotype of Reed Sternberg cells. Study of 50 cases of Hodgkin's disease using frozen fixed tissues. Cancer. 1989; 63:2083-2087.

10. Carbone, A., Gloghini, A., Gattei, V. et al. Expression of functionalCD40 antigen on Reed Sternbergcells and Hodgkin's disease cell lines. Blood 1995; 85:780-789.

11. Nelson, P.N., Reynold, G.M., Waldron, E.E., Ward, K, Giannopoulous, K.C., and Murray,P.G. Monoclonal antibodies. J. Clin. Pathology. 2000; 53:111-117.
12. Rappaport, H., Bernard, C.W., Butler, J.J., Portman, R.F., Lukes, R.J., and Thomas, L.B. Report of the Committee of histopathologic criteria contributing to staining of Hodgkin's disease. Cancer Res. 1971; 31:1864-1865.

13. Lukes, R.J. and Butler, J.J. The pathology and nomenclature of Hodgkin's disease. Cancer Res. 1966; 26:1063-108I.

14. Lukes, R.J., Graver, L.F.. Hall, T.C., Rappaport H., and Rubin P: Report of the Nomenclature Committee. Cancer Res. 1966; 26:1311, 1966.

15. Drury, R and Wallington, E.Carleton's Histological Technique. Oxford University Press, New York/Toronto 4th ed. 1967.

16. Tumwine, L.K., Wabinga, H. and Odida, M. Haematoxylin and eosin staining in the diagnosis of Hodgkin's disease in Uganda. East Afr Med. J. 2003; 80:119-23.

17. Dhru, R. and Templeton, A.C. Post mortem findings in Ugandans with Hodgkin's disease. Brit. I. Cancer. 1972; 26:331-334.

18. Riyat, M.S. Hodgkin's disease in Kenya. Cancer. 1992: 69:1047-1051

19. Levy, L.M. Hodgkin's disease in black Zimbabweans. A study of epidemiologic, histologic and, and clinical features. Cancer. 1988; 61:189-194.

20. Hesseling, P.B., Wessel, G., Van Jaarsveld, D. and Van Riet, F. Hodgkin's disease in children in southern Africa: epidemiological characteristics, morbidity and long term outcome. Ann. Trop. Paed. 1997: 17:367-373.

21. Von Wasielweski R, Mengel M, Fischer R. et al. Classical Hodgkin's disease: clinical impact of the immunophenotype. Amer. J. Pathology. 1997; 151:1128-1 130.

22. Monterosso, V., Zhou, Koo, S., Glackin, C., Bujan, W. and Meideros, J. Hodgkin's disease in Costa Rica: a report of 40 cases analysed for Epstein-Barr virus. Amer. J. Clin. Păthol. 1998; 109:618-624.

23. Peh, S.C., Looi, L.M. and Pallesen, G. Epstein-Barr virus and Hodgkin's disease in a multi ethnic population in Malaysia. Histopathology. 1997: 30:227-233.

24. Olweny, C.L.M., Ziegler, J.L., Bernard.C.W. and Templeton, A.C. Adult Hodgkin's disease in Uganda. Cancer Philad. 1971:27:1295-1301.

25. Wright, D.H. Lymphoreticular neoplasms. Recent results. Cancer Res. 1973; 41:270-291.

26. Glaser, S.L. Expert review of the diagnosis and histologic classification of Hodgkin's disease in a population based cancer registry. Cancer. 2002; 92:21 8-224.

27. Schmauz, R., Mugerwa, J.W. and Wright, D.H. The distribution of non-Burkitt's non-Hodgkin's Iymphoma in Uganda in relation to malarial endemicity. Int. J. Cancer. 1990; 45:650-653.

28. Taylor, C.R. Evolving concepts of the nature of Hodgkin's disease: a history. Amn. Diag. Pathol. 2000; 4:337-346. 